\title{
Choroidal invasion of retinoblastoma: metastatic potential and clinical risk factors
}

\author{
Carol L Shields, Jerry A Shields, Karin A Baez, Jacqueline Cater, Patrick V De Potter
}

\begin{abstract}
There is considerable debate about the significance of choroidal invasion of retinoblastoma with regard to metastatic disease. The charts of patients with retinoblastoma were reviewed over a 17 year period to determine the frequency of histopathological choroidal invasion of retinoblastoma and its risk for eventual metastatic disease. Sixty seven of 289 eyes (23\%) enucleated for retinoblastoma had histopathological evidence of choroidal invasion. Those patients with choroidal invasion (with or without optic nerve invasion) were more likely to develop metastases than those without choroidal invasion $(p=0.0001)$. When considering those patients with isolated choroidal invasion of retinoblastoma, excluding those with associated optic nerve invasion, there was no significant risk but there was a trend towards the development of metastases $(p=0 \cdot 10)$. The clinical factors found to be predictive for choroidal invasion from retinoblastoma from a univariate analysis included increased intraocular pressure $(p=0.04)$ and iris neovascularisation $(p=0.007)$ and, from a multivariate analysis, iris neovascularisation $(p=0.02)$. The histopathological factors statistically associated with choroidal invasion included the presence of optic nerve invasion $(p=0.002)$ and poorly differentiated retinoblastoma $(p=0.003)$. Factors not predictive for choroidal invasion included the age, race, and sex of the patient and the tumour laterality, inheritance, size, and growth pattern. Choroidal invasion of retinoblastoma is a risk for metastases, especially if it is associated with any degree of optic nerve invasion.

(Br f Ophthalmol 1993; 77: 544-548)
\end{abstract}

Ocular Oncology

Service, Wills Eye

Hospital, Philadelphia,

USA

C L Shields

J A Shields

K A Baez

P V De Potter

Department of

Biostatistics, Thomas

Jefferson University,

Philadelphia, USA

J Cater

Correspondence to:

Carol L Shields, MD

Oncology Service, Wills Eye

Hospital, 900 Walnut Street,

Philadelphia, PA 19107,

USA.

Accepted for publication

28 April 1993 blastoma, whereas choroidal invasion was not significantly associated with a fatal outcome. Although other studies have also suggested that choroidal invasion of retinoblastoma is not asso- ciated with a worse prognosis, ${ }^{13-15}$ several conflicting reports have indicated that choroidal invasion of retinoblastoma is associated with a poorer prognosis. ${ }^{51218-21}$ Messmer and associates in 1991 reported that the risk for metastatic disease increased when choroidal invasion was seen in association with optic nerve invasion and/or late enucleation. ${ }^{5}$ Olver and coworkers found that the two independent histological predictors for survival were the degree of optic nerve invasion and the degree of choroidal invasion and when the two factors existed together the prognosis worsened. $^{21}$

Because of the conflicting opinions regarding the significance of choroidal invasion or retinoblastoma, there has been controversy regarding the necessity of systemic chemotherapy and orbital radiotherapy in these cases. Earlier studies have addressed the relationship between histopathological presence of choroidal invasion and systemic prognosis. Our study was designed to investigate the prognostic significance of choroidal invasion of retinoblastoma and to determine clinical factors that may be associated with choroidal invasion. The presence of these clinical features may alert the ocular oncologist to the risk for choroidal invasion and possibly influence ultimate treatment.

\section{Patients and methods}

We reviewed the charts of all retinoblastoma patients who were evaluated at the Ocular Oncology Service at Wills Eye Hospital between February 1974 and August 1991. Those patients who were treated by enucleation and had at least 6 months of follow up were selected for this study. Patient clinical data evaluated included age, race, and sex. The ocular features evaluated included intraocular pressure (IOP), iris neovascularisation, fundus findings including specific tumour characteristics, visualisation of the optic nerve, and vitreous haemorrhage. The specific tumour characteristics evaluated were laterality, inheritance, prior treatment, largest tumour dimension ( $\mathrm{mm})$, largest tumour thickness (mm), growth pattern (exophytic, endophytic, or combination), and Reese-Ellsworth stage. The pathology report, based on approximately 30 routine histopathological sections made through the central region of the tumour and stained with haematoxylin and eosin, was reviewed for tumour differentiation as well as type and extent of optic nerve, subarachnoid, choroidal, and orbital extension. The develop- 
ment of eventual distant haematogenous metastases or pineal/parasellar tumour (trilateral retinoblastoma) was recorded.

\section{Results}

There were 441 patients with retinoblastoma managed on the Ocular Oncology Service at Wills Eye Hospital during the period of this study. Of these 441 patients, there were 360 eyes enucleated, 19 of which were bilateral enucleations. For this study the eye with the greatest tumour burden in the bilateral enucleation group was included and the less affected eye was excluded; therefore, 19 eyes were excluded from further evaluation. The 52 eyes that were enucleated at other institutions were also excluded from this study because the entire globe was not available to us for pathological evaluation. After these exclusions, the number of eyes evaluated in detail was 289.

The mean age of these 289 patients at the time of enucleation was 23 months (median 18; range 1-204 months). The mean follow up was 75 months (median 51; range 6-477 months). The patient group was then divided into those with and those without choroidal invasion of retinoblastoma. The following are evaluations of these two subgroups (Table 1).

\section{CHOROIDAL INVASION SUBGROUP}

There were 67 patients (23\%) with choroidal invasion of retinoblastoma. The patient mean follow up was 90 months (range 6-333 months). The patient mean age was 24 months (median 18;

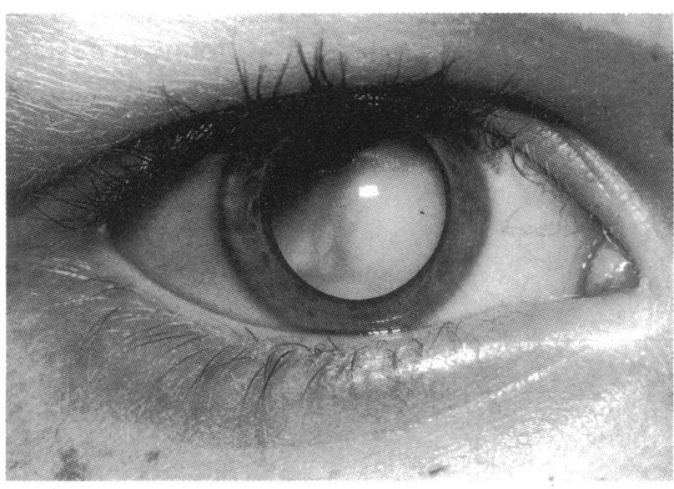

Fig $1 A$

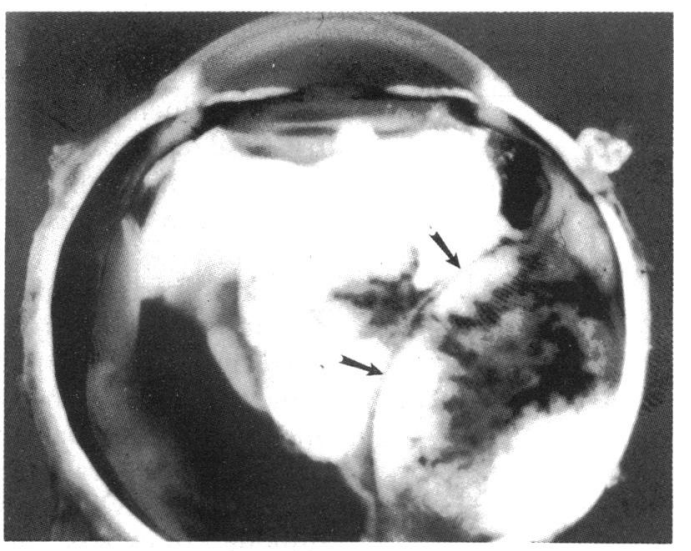

Fig $1 B$
Table 1 Retinoblastoma invasion of optic nerve and/or choroid as predictor of metastases

\begin{tabular}{|c|c|c|}
\hline Invasion site $(n)$ & p Value & Significance \\
\hline $\begin{array}{l}\text { Optic nerve }{ }^{\star}(84) \\
\text { Choroid† }(67) \\
\text { Choroid only } \neq(37) \\
\text { Optic nerve/choroid (30) } \\
\text { simultaneous }\end{array}$ & $\begin{array}{l}0.0016 \\
0.0001 \\
0 \cdot 10 \\
0 \cdot 0001\end{array}$ & $\begin{array}{l}\mathrm{S} \\
\mathrm{S} \\
\mathrm{T} \\
\mathrm{S}\end{array}$ \\
\hline
\end{tabular}

$\mathrm{S}=$ significant; $\mathrm{NS}=$ non-significant $\mathrm{T}=$ trend.

$\star$ Optic nerve invasion overall, regardless of the presence of choroidal invasion.

tChoroidal invasion overall, regardless of the presence of optic nerve invasion.

$\ddagger$ Choroidal invasion only, excluding all cases with simultaneous optic nerve and orbital invasion.

CConsidered only patients with both optic nerve and choroidal

invasion in the same eye.

1-120 months). There were 40 men and 27 women; 59 whites and eight blacks. The tumour was unilateral in 37 cases and bilateral in 30 cases; sporadic in 60 and familial in seven cases. Ten patients had treatment before enucleation such as external beam irradiation, plaque irradiation, laser photocoagulation, and cryotherapy.

The mean IOP was $25 \mathrm{~mm} \mathrm{Hg}$ (median 22 $\mathrm{mm} \mathrm{Hg}$; range $7-55 \mathrm{~mm} \mathrm{Hg}$ ). The IOP was $>22$ $\mathrm{mm} \mathrm{Hg}$ in 29 patients. Iris neovascularisation was seen in 30 cases.

The eye was classified as Reese-Ellsworth group 1 in no cases, group 2 in no cases, group 3 in three cases, group 4 in one case, group 5 in 61 cases, and unknown in two cases. The largest tumour dimension (LTD) was $\leq 15 \mathrm{~mm}$ in 37 patients and $>15 \mathrm{~mm}$ in 29 patients. The mean LTD was $15 \mathrm{~mm}$ and the mean largest tumour thickness was $11 \mathrm{~mm}$. The tumour was exophytic in 28 cases, endophytic in 22 cases, and a combination in 15 cases. Vitreous haemorrhage was present in 17 eyes.

Optic nerve invasion was seen histopathologically in 30 cases. The invasion was anterior to the lamina cribrosa in 11 cases, extended to the lamina cribrosa in seven cases, posterior to the lamina cribrosa but not to the site of optic nerve transection in four cases, and to the cut section of the optic nerve in no cases. Tumour cells were observed in the subarachnoid space in eight cases. Orbital invasion was present histopathologically in three cases. The tumour differention was poor in 35 , moderate in 23 , and well in eight.

Metastases developed in 13 patients, 10 of whom also had optic nerve invasion. When evaluating the 37 patients who had choroidal invasion without optic nerve invasion, metastases developed in three.

\section{NO CHOROIDAL INVASION SUBGROUP}

There were 222 patients without choroidal invasion of retinoblastoma. The patient mean follow up was 70 months (range $6-477$ months). The patient mean age was 23 months (median 18; range 6-204 months). There were 122 men and 100 women; 193 whites and 29 blacks. The tumour was unilateral in 132 cases and bilateral in 89 cases; sporadic in 211 and familial in 11 cases. Twenty seven patients had treatment before enucleation such as external beam irradiation, plaque irradiation, laser photocoagulation, and cryotherapy. 
The mean IOP was $21 \mathrm{~mm} \mathrm{Hg}$ (median 18 $\mathrm{mm} \mathrm{Hg}$; range $2-60 \mathrm{~mm} \mathrm{Hg}$ ). The IOP was $>22$ $\mathrm{mm} \mathrm{Hg}$ in 57 patients. Iris neovascularisation was seen in 60 cases.

Table 2 Clinical parameters in relation to histopathological choroidal invasion of retinoblastoma

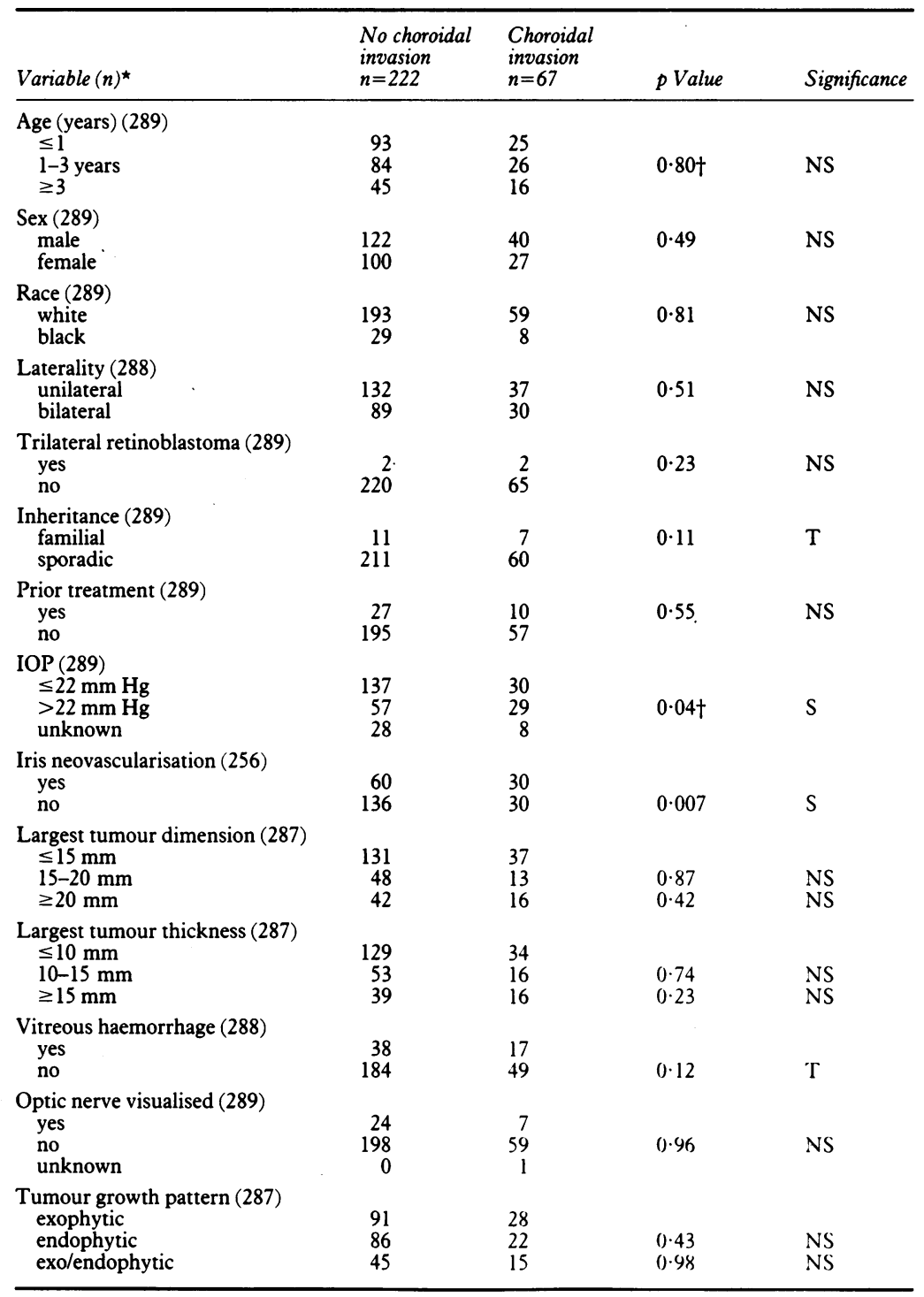

$S=$ significant; $N S=$ not significant; $T=$ trend.

*There were missing values in some charts therefore the number is not 289 in all cases. †Modelled as continuous linear variables, not discrete categories.

Table 3 Histopathological parameters in relation to choroidal invasion of retinoblastoma

\begin{tabular}{|c|c|c|c|c|}
\hline $\operatorname{Variable}(n)^{\star}$ & $\begin{array}{l}\text { No choroidal } \\
\text { invasion } \\
n=222\end{array}$ & $\begin{array}{l}\text { Choroidal } \\
\text { invasion } \\
n=67\end{array}$ & p Value & Significance \\
\hline $\begin{array}{l}\text { Tumour differentiation (267) } \\
\text { well } \\
\text { moderate } \\
\text { poor }\end{array}$ & $\begin{array}{l}48 \\
76 \\
77\end{array}$ & $\begin{array}{r}8 \\
23 \\
35\end{array}$ & $\begin{array}{l}0.05 \\
0.003\end{array}$ & $\begin{array}{l}S \\
S\end{array}$ \\
\hline $\begin{array}{l}\text { Optic nerve invasion (289) } \\
\text { absent } \\
\text { present } \\
\text { prelaminar } \\
\text { laminar } \\
\text { post-laminar } \\
\text { cut section } \\
\text { subarachnoid }\end{array}$ & $\begin{array}{r}166 \\
31 \\
13 \\
6 \\
1 \\
5\end{array}$ & $\begin{array}{r}37 \\
11 \\
7 \\
4 \\
0 \\
8\end{array}$ & $0.002 \dagger$ & $\mathrm{s}$ \\
\hline $\begin{array}{l}\text { Orbital invasion (276) } \\
\text { yes } \\
\text { no }\end{array}$ & $\begin{array}{r}2 \\
208\end{array}$ & $\begin{array}{r}3 \\
63\end{array}$ & 0.08 & $\mathrm{~T}$ \\
\hline
\end{tabular}

$S=$ significant; $N S=$ not significant; $T=$ trend.

$\star$ There were missing values in some charts therefore the number is not 289 in all cases. $\dagger P$ value for presence or absence of optic nerve invasion.
The eye was classified as Reese-Ellsworth group 1 in no cases, group 2 in no cases, group 3 in six cases, group 4 in six cases, group 5 in 199 cases, and unknown in 11 cases. The largest tumour dimension (LTD) was $\leq 15 \mathrm{~mm}$ in 131 patients and $>15 \mathrm{~mm}$ in 90 patients. The mean LTD was $15 \mathrm{~mm}$ and the mean largest tumour thickness was $11 \mathrm{~mm}$. The tumour was exophytic in 91 cases, endophytic in 86 cases, and a combination in 45 cases. Vitreous haemorrhage was seen in 38 cases.

Optic nerve invasion was seen histopathologically in 56 cases. The invasion was anterior to the lamina cribrosa in 31 cases, extended to the lamina cribrosa in 13 cases, posterior to the lamina cribrosa but not to the site of optic nerve transection in six cases, and to the cut section of the optic nerve in one case. Tumour cells were seen in the subarachnoid space in five cases. Orbital invasion was present in two cases. Tumour differentiation was poor in 77 , moderate in 76 , and well in 48 . Metastases developed in seven patients (Fig 1), five of whom had optic nerve invasion.

\section{STATISTICAL EVALUATION}

A univariate logistic regression analysis for the variables in Table 1 was performed to measure whether choroidal invasion (with and without optic nerve invasion) was a significant predictor of development of metastases. Those patients who developed metastases had a higher incidence of choroidal invasion $(p=0.0001)$. When extracting those patients with isolated choroidal invasion of retinoblastoma (excluding those with simultaneous optic nerve invasion) the development of metastasis showed only a trend of association ( $p=0 \cdot 10)$ (Table 1) (Fig 1). Clinical factors found to be statistically significant for risk of choroidal invasion of retinoblastoma included increased IOP $(p=0.04)$ and iris neovascularisation $(\mathrm{p}=0.007)$ (Table 2). Histopathological factors associated with choroidal invasion included presence of optic nerve invasion (not analysed for depth of optic nerve involvement) $(p=0.002)$ and poorly differentiated tumour $(\mathrm{p}=0.003)$ (Table 3).

The following clinical factors showed a trend but not statistical significance for risk for choroidal invasion: familial inheritance pattern $(p=0 \cdot 11)$ and vitreous haemorrhage $(p=0 \cdot 12)$. Histopathological evidence of orbital involvement also showed a trend of association with choroidal invasion $(p=0.08)$. Those factors found not to be a statistical risk for choroidal invasion included: age, sex, race, laterality, trilateral retinoblastoma, prior treatment, largest tumour dimension, largest tumour thickness, optic nerve visualisation, and tumour growth pattern.

A multivariate analysis using logistic regression for the variables with $p<0.30$ in Table 2 was performed. The most significant variables proved to be iris neovascularisation $(\mathbf{p}=0.02)$ and degree of tumour differentiation (well $v$ poor $[p=0.05])$. Neovascularisation of the iris correlated with IOP, vitreous haemorrhage, and tumour thickness at the following levels $\mathrm{p}<0.0001, \mathrm{p}=0 \cdot 03, \mathrm{p}=0 \cdot 10$, respectively. 


\section{Discussion}

It is generally agreed that the risk for metastasis from retinoblastoma increases with degree of optic nerve invasion and orbital invasion of the tumour. ${ }^{4-622}$ The presence of choroidal invasion of retinoblastoma has been shown by some to increase the risk for metastases. ${ }^{51216-20}$ In correlation with other studies, ${ }^{45}$ our study found that choroidal invasion of retinoblastoma was present in $67(23 \%)$ of 289 enucleated eyes based on routine histopathological sections through the centre of the tumour. Overall, we found that choroidal invasion was a significant predictor of metastases. In 30 of these cases, the choroidal invasion was present simultaneously with optic nerve invasion and statistical analysis of this subgroup demonstrated a highly significant risk for metastases. In 37 cases only choroidal invasion was present (without optic nerve invasion) and in these cases the development of metastases was not significantly associated but showed a trend of association with isolated choroidal invasion (Fig 1) (Table 1). From our results, isolated choroidal invasion of retinoblastoma did not statistically increase the risk for metastases but when associated with any degree of optic nerve invasion the risk was significant. This has also been observed by Messmer and associates ${ }^{5}$ and Olver and associates. ${ }^{21}$ It should be understood that our data and the data of others regarding metastatic potential of retinoblastoma are clouded by the fact that some of the patients with choroidal and/or optic nerve invasion received prompt radiotherapy and/or chemotherapy so that the incidence of metastases may be different from what would be expected in untreated cases.

We evaluated the histopathological features in this study from representative gross observations and histopathological sections of routinely processed eyes. Our goal was to determine if choroidal invasion in representative sections was predictive of metastatic disease. It would have been impractical to cut serial sections through every eye. Without serial sectioning it is possible that small degrees of choroidal invasion could be missed. This argument is true of any neoplasia that is not serially sectioned when evaluating cell type, mitotic activity, or invasiveness. We did not artificially classify the choroidal invasion into minor or major tumour invasion as we believed that the division would be too subjective for our goals. We therefore classified the eyes into presence or absence of choroidal invasion as we believed this approach to be more objective. Others though have found that the degree of choroidal invasion as judged by subjective assessment was an accurate predictor of survival. ${ }^{21}$

A secondary goal of our study was to determine, we believe for the first time, the clinical features that may be associated with a higher risk for choroidal invasion of retinoblastoma (Table 2 ). We found that the clinical factors that significantly predict choroidal invasion of retinoblastoma were increased IOP and iris neovascularisation .(Table 2). Histopathological factors that predict choroidal invasion were poorly differentiated tumour and optic nerve invasion (Table 3). It appears that elevated IOP may play a role in the development of optic nerve and choroidal invasion of retinoblastoma. The exact mechanism is unclear but one might speculate that the high pressure may somehow force tumour cells into the optic nerve and also cause breakdown of the retinal pigment epithelium/ Bruch's membrane complex and allow access of tumour to the choroid. The role of increased IOP in the development of Schnabel's cavernous atrophy of the optic nerve and intraneural infiltration of silicone oil has been demonstrated. ${ }^{2324}$

One might expect that an exophytic tumour is more likely to invade through the retinal pigment epithelium/Bruch's membrane complex into the choroid because its growth pattern is subretinal and toward the choroid. ${ }^{25}$ However, our evaluation showed that exophytic tumours show no higher risk for choroidal invasion than endophytic tumours. The retinal pigment epithelium/ Bruch's membrane complex seems to demonstrate a unique resistance to this neoplasm..$^{25}$ This resistance may be disrupted in the presence of high IOP.

From both the univariate and multivariate analyses, neovascularisation of the iris was found to be the most important clinical risk factor. In most cases of iris neovascularisation there was associated neovascular glaucoma. In the multivariate analysis, iris neovascularisation correlated with IOP, vitreous haemorrhage, and tumour thickness. The incidence of iris neovascularisation in our study was $35 \%$. Walton and $\mathrm{Grant}^{26}$ showed that $44 \%$ of 88 eyes enucleated with retinoblastoma had iris neovascularisation. They did not mention the frequency of glaucoma in their series, but we have shown in this study that elevated IOP was present in 34\% of eyes enucleated for retinoblastoma. In earlier studies from our department we found clinical evidence of elevated IOP in $17 \%$ of all patients with retinoblastoma (regardless of the method of treatment) and the mechanisms of elevation as judged clinically were neovascular glaucoma in $74 \%$, angle closure glaucoma in $27 \%$, and trabecular meshwork infiltration in $2 \%{ }^{27}$

From a practical standpoint, when the clinician is faced with a child with retinoblastoma and there is iris neovascularisation or elevated IOP, we believe that enucleation is the treatment of choice. If isolated choroidal invasion (without optic nerve invasion) is documented histopathologically then the benefits of prophylactic chemotherapy and/or radiotherapy must be discussed with the paediatric oncologist, radiation oncologist, and patient's family. Treatment is debatable because of the carcinogenic and other secondary effects of chemotherapy and radiotherapy in these children who may be prone to second cancers weighed against the relatively low overall incidence of metastatic retinoblastoma. If choroidal invasion is present in association with any degree of optic nerve invasion then prophylactic orbital radiotherapy and/or systemic chemotherapy may be indicated. Perhaps a clinical trial evaluating the role of prophylactic chemotherapy in patients with choroidal invasion of retinoblastoma is indicated.

Supported by the Macula Foundation, New York, NY and the Eye Tumor Research Foundation, Philadelphia, PA, USA. 
1 Shields JA, Shields CL. Intraocular tumors: $a$ text and atlas. Philadelphia: Saunders, 1992: 377-92.

2 Ellsworth R.M. The practical management of retinoblastoma. Trans Am Ophthalmol Soc 1969; 67: 462-534.

3 Sang DN, Albert DM. Retinoblastoma: clinical and histopathologic features. Hum Pathol 1982; 13: 133-47.

4 Kopelman JE, McLean IW, Rosenberg SH. Multivariate analysis of risk factors for metastasis in retinoblastoma analysis of risk factors for metastasis in retinoblas

5 Messmer EP, Heinrich T, Hopping W, deSutter E, Havers W, Sauerwein W. Risk factors for metastases in patients with retinoblastoma. Ophthalmology 1991; 98: 136-41.

6 Magramm I, Abramson DH, Ellsworth RM. Optic nerve involvement in retinoblastoma. Ophthalmology 1989; 96: 217-22

7 Haye C, Desjardins L, Elmaleh C, Schlienger P, Zucker JM Laurent M. Prognosis and treatment of retinoblastoma. 10 cases treated at Institut Curie. Ophthalmic Paediatr Genet 1989; 10: 151-5.

8 Erwenne CM, Franco EL. Age and lateness of referral as determinants of extraocular retinoblastoma. Ophthalmic Paediatr Genet 1989; 10: 179-84.

9 Rootman J, Ellsworth RM, Hofbauer J, Kitchen D. Orbital extension of retinoblastoma: a clinicopathological study. Can f Ophthalmol 1978; 13: 72-80.

10 el Massri A. Various patterns of involvement of the optic disc in retinoblastoma. Metab Pediatr Syst Ophthalmol 1990; 13: $15-9$.

11 Tosi $\mathrm{P}$, Cintorino $\mathrm{M}$, Toti $\mathrm{P}$, Ninfo V, Montesco MC Frezzotti $R$, et al. Histopathological evaluation for the prognosis of retinoblastoma. Ophthalmic Paediatr Genet 1989; 10: 173-7.

12 Rootman J, Hofbauer J, Ellsworth RM, Kitchen D. Invasion of the optic nerve by retinoblastoma: a clinicopathologic study. Can $\mathcal{F}$ Ophthalmol 1976; 11: 106-14.

13 Redler LD, Ellsworth RM. Prognostic importance of choroidal invasion in retinoblastoma. Arch Ophthalmol 1973; 90: $294-6$.

14 Kobrin JL, Blodi FC. Prognosis in retinoblastoma: influence of histopathologic characteristics. $\mathcal{F}$ Pediatr Ophthalmol Strabismus 1978; 15: 278-81.

15 Stannard C, Lipper S, Sealy R, Sevel D. Retinoblastoma: correlation of invasion of the optic nerve and choroid with prognosis and metastases. $\mathrm{Br} \mathcal{F}$ Ophthalmol 1979; 63: 560-70.

16 Parkhill EM, Benedict WL. Gliomas of the retina, a histopathologic study. Am $\mathcal{F}$ Ophthalmol 1941; 24: 1354-73.

$17 \mathrm{Herm}$ RJ, Heath P. A study of retinoblastoma. Am f Ophthalmol 1956; 41: 22-30.

18 Zimmerman LE. The registry of ophthalmic pathology; past, present, and future. XVII Jackson Memorial Lecture. Trans Am Acad Ophthalmol Otolaryngol 1961; 65: 51-113.

19 Brown DH. The clinicopathology Am 7 Ophthalmol 1976; 61: 508-14.

20 Carbajal UM. Metastasis in retinoblastoma. Am $\mathcal{f}$ Ophthalmo 1959; 48: 47-69.

21 Olver J, McCartney ACE, Kingston J, Hungerford J. Histological indicators of the prognosis for survival following enucleation for retinoblastoma. In: Bornfeld N, Gragoudas ES, Hopping W, Lommatzsch PK, eds. Tumors of the eye. New York: Kugler, 1991: 59-67.

22 Shields JA. Diagnosis and management of orbital tumors. Philadelphia: Saunders, 1989: 341-77.

23 Zimmerman LE, De Venecia G, Hamasaki DI. Pathology of the optic nerve in experimental acute glaucoma. Invest the optic nerve in experimer

24 Shields CL, Eagle RC. Pseudo-Schnabel's cavernous egeneration of the optic nerve secondary to intraocular silicone oil. Arch Ophthalmol 1989; 107: 714-7.

25 Wolter JR. Retinoblastoma extension into the choroid. Pathological study of the neoplastic process and thoughts about its prognostic significance. Ophthalmic Paediatr Genet 1987; 8: prognosic

26 Walton DS, Grant WM Retinoblastoma and iris neovascularization. Am f Ophthalmol 1968; 65: 598-9.

27 Shields CL Shields JA, Shields MB, Augsburger JJ. Prevalence and mechanisms of secondary intraocular pressure elevation in eyes with intraocular tumors. Ophthalmology 1987; 94: 839-46. 